Technological University Dublin

DÜBLIN

ARROW@TU Dublin

2012-11-12

\title{
A 2.45/5.8 GHz Folded Monopole Antenna for WLAN Applications
}

Abraham Loutridis

Technological University Dublin, d11125656@mydit.ie

Matthias John

Technological University Dublin, matthias.john@tudublin.ie

Giuseppe Ruvio

Technological University Dublin

See next page for additional authors

Follow this and additional works at: https://arrow.tudublin.ie/ahfrccon

Part of the Systems and Communications Commons

\section{Recommended Citation}

Loutridis, A. et al. (2012 A 2.45/5.8 GHz Folded Monopole Antenna for WLAN Applications, LAPC Loughborough Antennas \& Propagation Conference, Loughborough, UK, pp. 1-3, 12/11/2012, doi:10.1109/LAPC.2012.6403003

This Conference Paper is brought to you for free and open access by the Antenna \& High Frequency Research Centre at ARROW@TU Dublin. It has been accepted for inclusion in Conference Papers by an authorized administrator of ARROW@TU Dublin. For more information, please contact arrow.admin@tudublin.ie, aisling.coyne@tudublin.ie,gerard.connolly@tudublin.ie. Funder: SFI 
Authors

Abraham Loutridis, Matthias John, Giuseppe Ruvio, and Max Ammann

This conference paper is available at ARROW@TU Dublin: https://arrow.tudublin.ie/ahfrccon/34 


\title{
A 2.45/5.8 GHz Folded Monopole Antenna for WLAN Applications
}

\author{
Abraham Loutridis ${ }^{1,2}$, Matthias John ${ }^{2}$, Giuseppe Ruvio ${ }^{1}$ and Max J. Ammann ${ }^{1}$ \\ ${ }^{1}$ Antenna \& High Frequency Research Centre, \\ ${ }^{2}$ CTVR the Telecommunication Research Centre \\ Dublin Institute of Technology, \\ Kevin Street, Dublin 8, Ireland \\ abraham.loutridis@mydit.ie \\ [matthias.john | giuseppe.ruvio|max.ammann]@dit.ie
}

\begin{abstract}
A probe-fed printed folded monopole antenna for WLAN applications is presented. The antenna operates at $2.45 \mathrm{GHz}$ and $5.8 \mathrm{GHz}$, is compact and has omni-directional characteristics in both bands. A parametric study of key geometrical parameters is reported.
\end{abstract}

\section{INTRODUCTION}

In recent years wireless communications industry has proliferated, with portable devices becoming smaller and more demanding in terms of data throughput and broadband operation. For the antenna designers it presents new challenges to design compact antennas covering smaller areas and maintaining good performance.

Because of the low profile and compact size of the planar and printed antennas [1], there is a strong preference to this type of antennas for applications such as WLAN, UWB, LTE and RFID [2]. Several dual-band and wideband printed and planar monopole antennas [3]-[5] were designed to meet the needs of these applications.

A conventional printed Inverted-F-Antenna (PIFA) [1], [6] covers almost all of these requirements, but usually demands one long dimension on the Printed Circuit Board (PCB) due to the aspect-ratio. A printed folded (hairpin) monopole antenna [7], [8] without the extensive horizontal arm offers smaller size, dual-band operation with a second resonance which is closer to the first resonance than the PIFA, good omnidirectional radiation characteristics, high efficiency and easy to manufacture.

In this paper, an investigation of the performance of a printed folded monopole antenna located on a conventional ground plane is presented. The effects of the geometrical characteristics of the folded monopole on the radiation performance of the antenna are investigated.

\section{ANTENNA DESIGN}

A printed folded monopole was designed for the WLAN $(2.45$ and $5.8 \mathrm{GHz})$ frequency range and placed on a conventional ground plane. The structure and coordinate system of the antenna is shown in Fig. 1. A $70 \mathrm{~mm} \times 70 \mathrm{~mm}$ Brass ground plane with a thickness of $0.15 \mathrm{~mm}$ was used. The folded monopole is printed on FR-4 $\left(\varepsilon_{\mathrm{r}}=4.3, \tan \delta=0.025\right.$, thickness $=1.6 \mathrm{~mm}$ ) with dimensions $22.2 \mathrm{~mm} \times 17 \mathrm{~mm}$. The printed folded monopole antenna is designed for $2.45 \mathrm{GHz} / 5.8 \mathrm{GHz}$ and the height of the monopole is $h=20.2 \mathrm{~mm}\left(\approx 0.165 \lambda_{0}\right)$. The width of the shorting strip of the antenna is $s=0.5 \mathrm{~mm}$ and the feeding strip width is $f=1.98 \mathrm{~mm}$. The length of the horizontal arm of the antenna is $l=10.5 \mathrm{~mm}$ and the width $a=3.57 \mathrm{~mm}$. The perimetric length of the antenna is $53.38 \mathrm{~mm}\left(\approx 0.44 \lambda_{0}\right)$. The monopole is fed via a 50 $\Omega$ SMA connector through the ground plane.

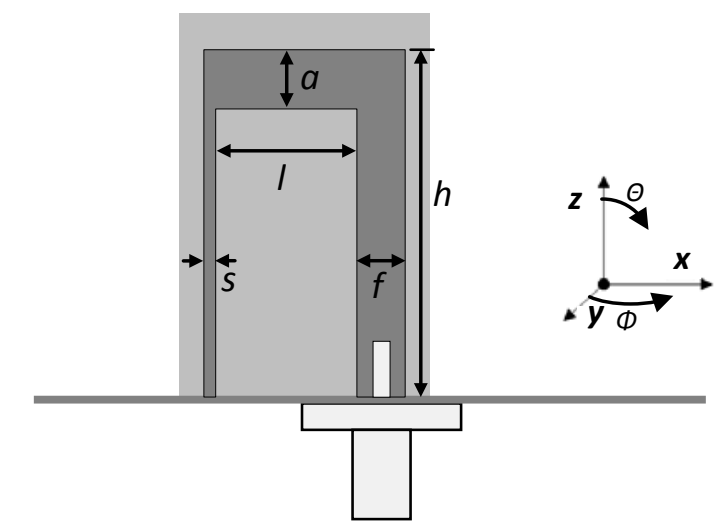

Fig. 1 Printed folded monopole antenna geometry and coordinate system

\section{RESULTS AND DISCUSSION}

In Figs. $2-5$ a parametric investigation of the variation of S11 with respect to the three most important geometric parameters of the printed folded monopole antenna are illustrated. Fig. 2 shows the simulated S11 (CST Microwave Studio, time domain solver) as a function of the height $h$ of the antenna. The results indicate that both resonant frequencies can be effectively controlled by selecting the proper value of $h$ but with greater sensitivity for the higher frequency. 


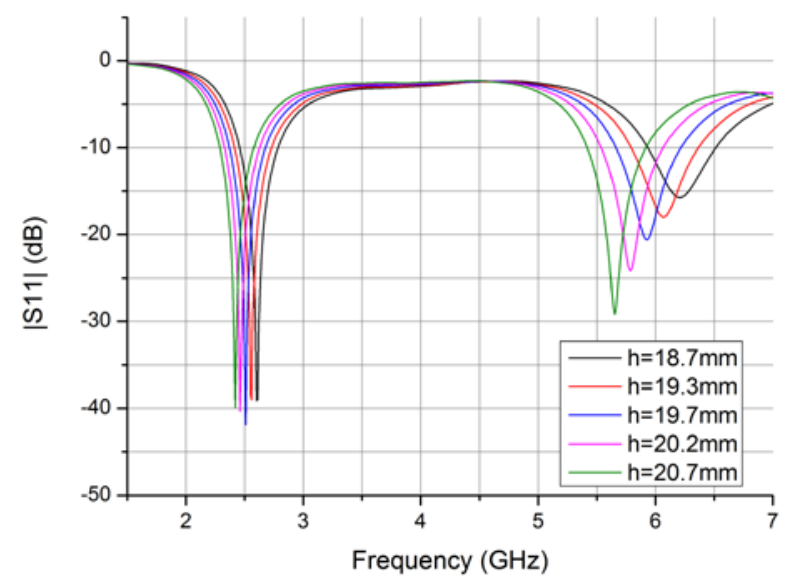

Fig. 2 The simulated S11 dependence on the height $(h)$ of the monopole

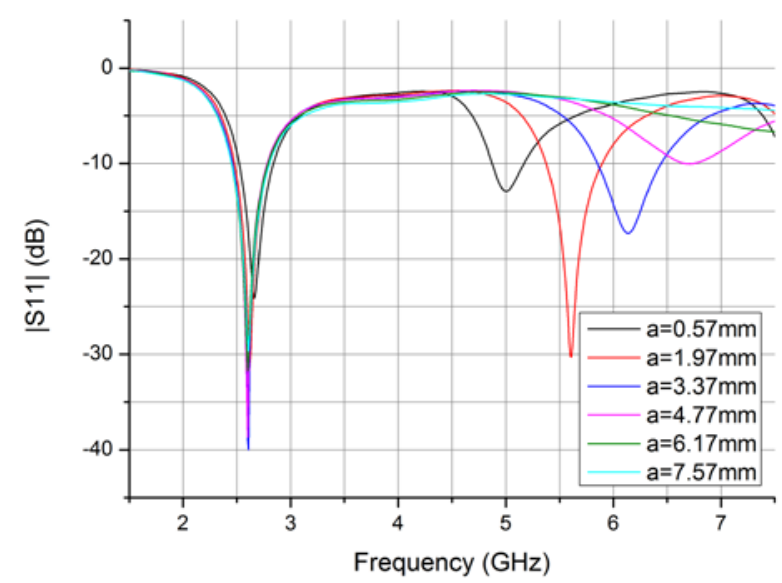

Fig. 3 The simulated S11 dependence on the width $(a)$ of the horizontal strip of the monopole

Fig. 3 shows the variation of the width $a$ of the horizontal strip of the monopole. From the graph it is clearly visible that increasing the value $a$ shifts the second resonance upwards with little effect on the lower resonance. The frequency ratio between the upper and the lower resonance $f_{R}=f_{2} / f_{1}$ continuously increases from 1.879 to 3.819 as the value of $a$ changes from $0.57 \mathrm{~mm}$ to $7.57 \mathrm{~mm}$. Hence this antenna offers a large controllable frequency ratio range.

In Fig. 4, simulated results for length $l$ varied from 8.0175 to $15.5175 \mathrm{~mm}$ are shown. Obtained results clearly show that both resonant frequencies can be effectively controlled (impedance matching and frequency shifting) by the parameter $l$.

Finally, Fig. 5 shows the simulated and measured S11 results of the proposed optimised antenna, which are in a good agreement. The lower band has a $-10 \mathrm{~dB}$ impedance bandwidth of $300 \mathrm{MHz}(2.34-2.64 \mathrm{GHz})$ for the simulated results and $280 \mathrm{MHz}(2.32-2.6 \mathrm{GHz})$ for the measured results. For the upper band the simulated results provide $530 \mathrm{MHz}$ (5.56-6.09 GHz) bandwidth, while the measured results provide $500 \mathrm{MHz}(5.61-6.11 \mathrm{GHz})$ bandwidth.

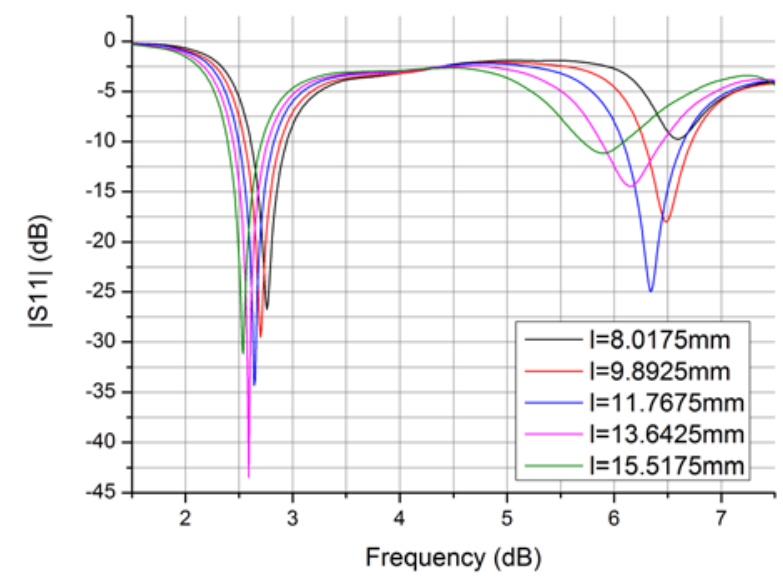

Fig. 4 The simulated S11 dependence on the length $(l)$ of the monopole.

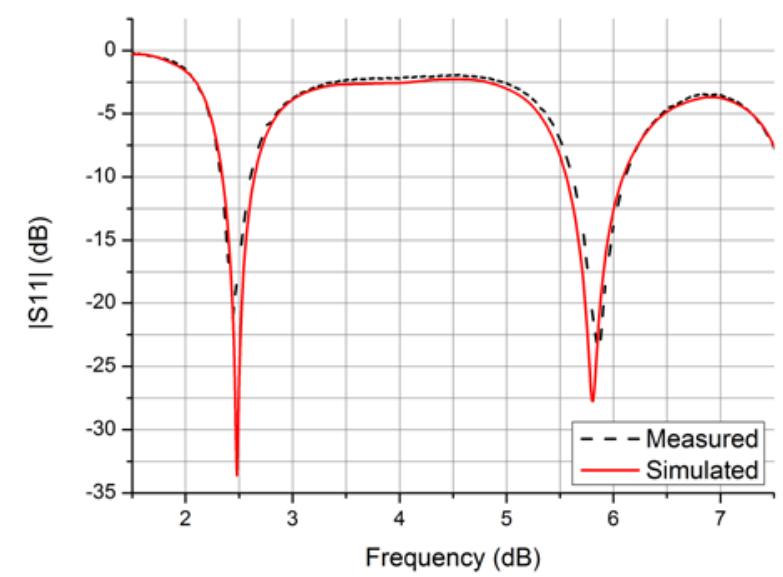

Fig. 5 Simulated and measured S11 for the printed folded monopole antenna

In Figures 6 - 9 the simulated and measured azimuth (x-y) and elevation $(\mathrm{x}-\mathrm{z})$ plane radiation pattern at 2.45 and $5.8 \mathrm{GHz}$ are illustrated for the antenna with dimensions given in Section 2. All the measured gain patterns are illustrated against the simulated patterns in $10 \mathrm{~dB} /$ division scaled plots. Moreover, each radiation pattern cut is presented together with the cross-polar component.

At the lower frequency it is seen that the omnidirectional pattern provides good polarization discrimination in the azimuth plane. Cross-polar components in the higher frequency in both planes are due to the greater flow of current in the horizontal strip of the monopole. Simulated total efficiencies are $98 \%$ for the first resonance and $90 \%$ for the second resonance. 


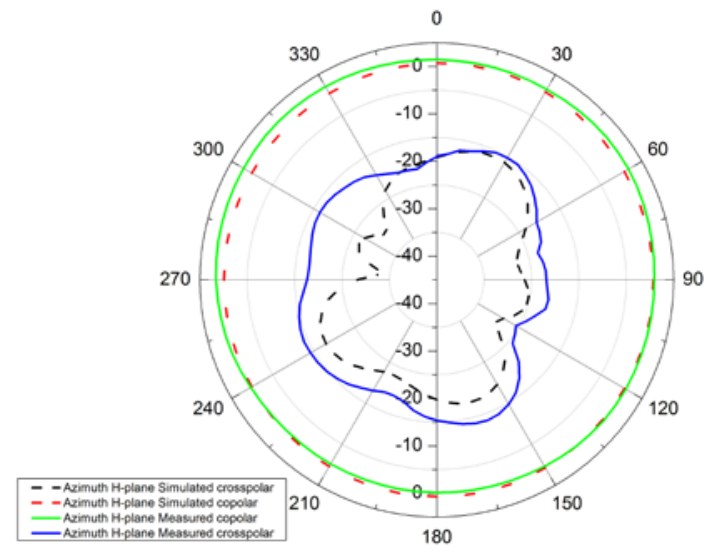

Fig. 6 Measured and simulated azimuth plane patterns at $2.45 \mathrm{GHz}$

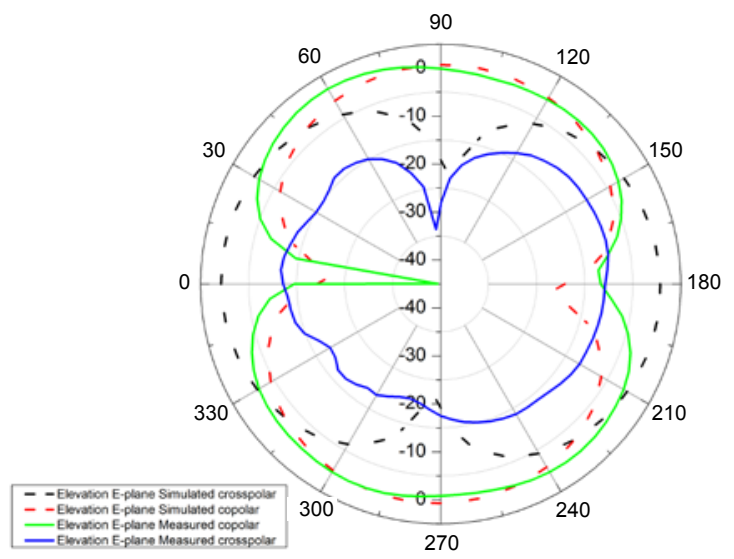

Fig. 7 Measured and simulated elevation plane patterns at $2.45 \mathrm{GHz}$

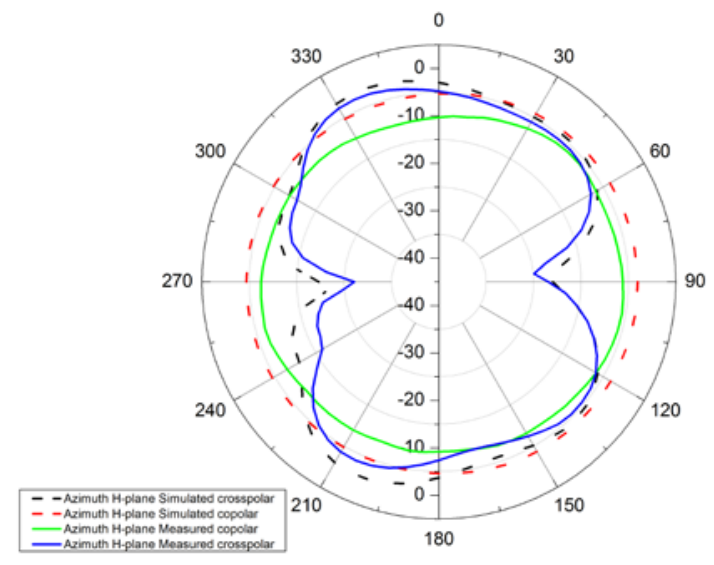

Fig. 8 Measured and simulated azimuth plane patterns at $5.8 \mathrm{GHz}$

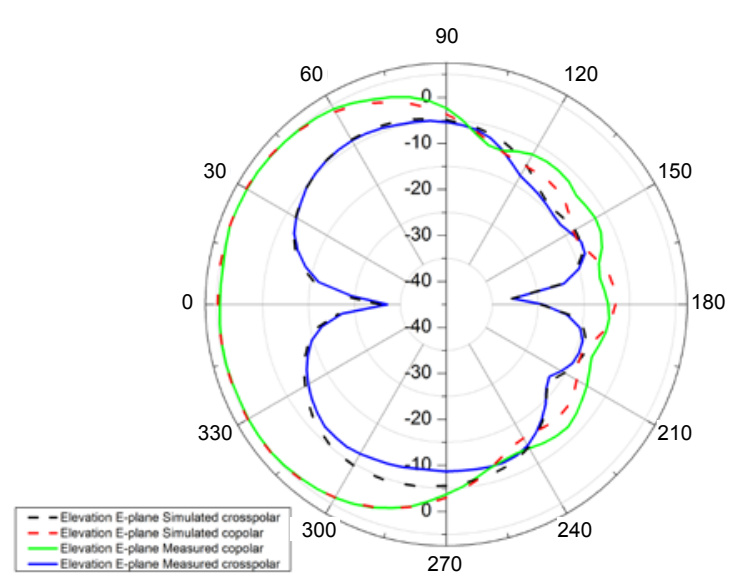

Fig. 9 Measured and simulated elevation plane patterns at $5.8 \mathrm{GHz}$

Considering the above results and compared with a typical Printed Inverted-F Antenna (PIFA) the proposed antenna offers a wide frequency ratio range with omnidirectional characteristics for both frequency bands.

\section{CONCLUSIONS}

In this paper an investigation of the performance of a printed folded monopole antenna in the WLAN range is presented. A dual band operation has been obtained and good radiation characteristics have been observed in both frequencies. Moreover the proposed antenna is easy to manufacture at a low cost, with additional benefit of a large frequency ratio range which is easy to control.

\section{ACKNOWLEDGMENT}

This material is based upon works supported by the Science Foundation Ireland under Grant No. 10/CE/I1853.

\section{REFERENCES}

[1] K-L. Wong, "PLANAR ANTENNAS FOR WIRELESS COMMUNICATIONS", Wiley, New Jersey, 2003.

[2] Z. N. Chen, M. J. Ammann, X. M. Qing, X. H. Wu, T. S. P. See and A. Cai, "Planar Antennas," IEEE Microwave Magazine, vol. 7, no. 6, $12 / 2006$.

[3] M. J. Ammann, J. A. Evans, and Z. Wu, "A Novel Hybrid Inverted-L Antenna with Wide Bandwidth", International Conference on Antennas and Propagation (ICAP 2003), vol. 2, pp. 720-722, 03/2003.

[4] G. Ruvio and M. J. Ammann, "A Novel Wideband Semi-Planar Miniaturized Antenna", IEEE Transactions on Antennas \& Propagation, vol. 55, issue 6, pp. 1760-1767, 06/2007.

[5] G. Ruvio, and M. J. Ammann, "A Novel Small Wideband Monopole Antenna", LAPC - Loughborough Antennas \& Propagation Conference, Loughborough, UK, pp. 189-192, 11/04/2006.

[6] Ryu, H.-K.; Kim, E.; Woo, J.-M., "'Miniaturisation of printed inverted-F antenna using chip coupler for Bluetooth applications", IEEE Electronic Letters, vol. 46, issue 13, pp. 883-885, 2010.

[7] C. C. Lin, "Dual-Band Folded Monopole Antenna with Slotted Ground Plane for WLAN Applications", Progress in Electromagnetics Research Letters, vol. 15, pp. 53-60, 2010.

[8] T. Papatheologou, A.B. Smolders, and U. Johannsen, "A Hairpin Antenna-in-Package Concept for RFID Tag Applications", IEEE Radio and Wireless Symposium (RWS), pp. 54-57, 2011. 